\title{
ARCIMBOLDO, LA HISTORIA NATURAL EN 2666*
}

\author{
Raúl Rodríguez Freire \\ rodriguezfreire@gmail.com \\ Pontificia Universidad Católica de Valparaíso
}

Aquel en quien el recuerdo sigue viviendo atrae la cólera de los otros que sólo pueden continuar viviendo en el olvido.

W.G. Sebald, Campo Santo (1982)

No me diga que este Arcimboldi no veía las cosas con audacia degenerada.

Jorge Baron Biza, El desierto y su semilla (1998)

RESUMEN / ABSTRACT

El ensayo pretende dar cuenta de la forma en que a lo largo de su obra Roberto Bolaño ha considerado la pintura del artista italiano Giuseppe Arcimboldo. Para ello se discute en primer lugar la lectura propuesta por Sergio Marras, y luego de argumentar su desacierto, se propone leer la textualización de Las estaciones y Los elementos a partir de la idea de historia natural, propuesta por Theodor Adorno y W. G. Sebald. Ello implicaría que la inclusión de tales pinturas de Arcimboldo se deben al intento por dar cuenta de un mundo en descomposición.

Palabras ClaVE: Bolaño, Arcimboldo, historia natural, descomposición. CONICYT.

El presente ensayo forma parte del proyecto número 3130597, financiado por 
This essay shows the way in which Roberto Bolaño consideres in his novels the painting of the Italian artist Giuseppe Arcimboldo. First, it discusses the reading proposed by Sergio Marras for arguing his blunder, and after it suggests to read the textualización of The stations and The elements based on the idea of natural history, proposed by Theodor Adorno and W.G. Sebald. It would imply that the incorporation of such Arcimboldo's paintings attempt to reveal the world in decomposition.

KEYWORDS: Bolaño, Arcimboldo, natural history, rotting.

"Y allí estaba yo. Y ellas me vieron y yo las vi. ¿Y qué fue lo que vi? Ojeras. Labios partidos. Pómulos brillantes [...] Recuerdo que me fijé en su rostro. Recuerdo que bebí su rostro hasta la última gota intentando dilucidar el carácter, la psicología de semejante individuo [que acompañaba a aquellas mujeres]. Lo único que queda de él en mi memoria, sin embargo, es el recuerdo de su fealdad. Era feo y tenía el cuello extremadamente corto. En realidad, todos eran feos. Las campesinas eran feas y sus palabras incoherentes. El campesino quieto era feo y su inmovilidad incoherente. Los campesinos que se alejaban eran feos y su singladura en zigzag incoherente. Que Dios me perdone y los perdone. Almas perdidas en el desierto" (Nocturno de Chile 31-33).

Cercanía, lejanía, la percepción mediada por la distancia, distancia que inscribe el lugar desde el que se observa en lo observado; es más, que determina aquello que se observa, que permite su sentido o sus sentidos. Tal es lo que permite ver un cuerpo, un rostro o sus partes, incluso cuando éstas se encuentran en movimiento. Perdido en los bosques que rodeaban el fundo llamado Là-bas-expresión que también refiere distancia, allá lejos, como la novela de Joris-Karl Huysmans-, el crítico Sebastián Urrutia Lacroix se encuentra intempestivamente con un grupo de campesinos: "lo que vi, a unos treinta metros de distancia, fue a dos mujeres y a dos hombres... con las manos tapando sus caras" (30), fisonomías cuyas partes constitutivas logró diferenciar prontamente puesto que al verlo, los campesinos se le acercaron: “Ojeras. Labios partidos. Pómulos brillantes" (31), la fragmentación del rostro en la cercanía. Ya no cuerpos, ya no caras, solo sus partes. Y cuando Urrutia Lacroix logra recomponer el rompecabezas, afirma que todos son feos, y que su habla es incoherente, como también lo es su andar. Pero no solo 
eso, sus rostros tampoco permanecían impávidos ante la mirada escrutadora: "sólo sonreían o adoptaban gestos de adustez o de fingida sorpresa, sus rostros antes inexpresivos iban del misterio a la iluminación, se contraían en interrogantes mudas o se expandían en exclamaciones sin palabras" (32), como si estuviéramos ante un cuadro de Francis Bacon, aunque aquí las figuras se encuentran de pie y su movimiento no es solo físico sino también psicológico.

Pero lo que me interesa, lo que en verdad me inquieta de estas visiones, es que acontecen inmediatamente después de que Urrutia Lacroix recordara el nombre de Giuseppe Arcimboldo, y ello gracias a la visualización de un conjunto de frutas y verduras, "materiales" que el artista italiano inscribiera en la tela representando un amorfo rostro, un nombre, por tanto, que no le permite imaginar la belleza de las estaciones, sino la fealdad y la decadencia de la vida humana.

No estaba enfrente de la casa principal sino de unos huertos que parecían dejados de la mano de Dios. Escuché, sin sorpresa, el ladrido de unos perros que no vi y al cruzar los huertos, donde bajo la sombra protectora de unos paltos se cultivaba toda clase de frutos y verduras dignas de un Archimboldo, distinguí a un niño y a una niña que cual Adán y Eva se afanaban desnudos a lo largo de un surco de tierra. El niño me miró: una ristra de mocos le colgaba de la nariz al pecho. Aparté rápidamente la mirada pero no pude desterrar unas náuseas inmensas... Cuando por fin pude controlar las arcadas el niño y la niña habían desaparecido. Después llegué a una especie de gallinero. Pese a que el sol aún estaba alto vi a todas las gallinas durmiendo sobre sus palos sucios... Más allá había un establo y una cochiquera. Los rodeé. Al otro lado se erguía una araucaria ¿Qué hacía allí un árbol tan majestuoso y bello? (29. Énfasis agregado).

La percepción directa, cercana, de unos rostros arcimboldianos tiene un efecto estremecedor, parece señalar Urrutia Lacroix, a tal punto, que "la visión ( $y$ todo lo que ella conlleva), pese a su brevedad, consiguió alterar mi equilibrio mental y físico" (30. Énfasis agregado). Reparo aquí en "y todo lo que ella conlleva", pues, qué es lo que estará en juego al momento de mirar a un grupo de campesinos y sus hijos, ¿qué es lo que atormenta a nuestro augusto crítico? En verdad, la respuesta se nos oculta, dado que pronto se retira, se aleja, redirigiendo sus pasos hacia Là-bas, donde encuentra a Neruda recitando para una pequeña y selecta audiencia. No obstante, ya sabemos que una visión como aquella conlleva algo más que una simple mirada. Bolaño lo sabe, dado que conoce muy bien el trabajo de Giuseppe Arcimboldo. Un huerto, frutas y 
verduras, niños y gallinas, así como los lugares en que se guardan el ganado (establos) y los cerdos (cochiquera), todo ello no hace sino convocar a las famosas cabezas compuestas de Arcimboldo, un pintor convencionalmente asociado a la inventiva y a las bromas, pero que se nos presenta aquí asociado a lo grotesco, a la suciedad, a las emanaciones putrefactas de los cuerpos, humanos y animales; Arcimboldo, parece vislumbrar Bolaño, es, sí, un pintor de lindas y atractivas cabezas, pero también, como veremos pronto, de aquello que reconocemos bajo el nombre de decadencia. Que su nombre inspire el nombre que se dará un tímido Hans Reiter, hijo de un cojo y de una tuerta, y que por años se asemejó más a un alga que a un ser humano, conlleva más de lo que hasta ahora hemos visualizado.

Ya es (casi) un lugar común señalar que la escritura de Roberto Bolaño está atravesada por el arte, que uno de sus recursos centrales es la écfrasis y que pone en juego de diversas maneras. Por ejemplo, insertando pintores y cuadros en sus novelas (Nocturno de Chile, Los detectives Salvajes, Amuleto, 2666, como también la póstuma Los sinsabores del verdadero policía), obras que luego serán descritas detalladamente, o creando personajes centrales cuyo oficio es el arte plástico (2666, Estrella distante). En cualquiera de ellas, Bolaño presenta al arte cumpliendo un objetivo determinado: desacralizar al arte mismo, inscribiendo así la conocida sentencia benjaminiana: "todo documento de cultura es a la vez un documento de barbarie". La imitación del ready-made duchampiano que Amalfitano realiza en el desierto de Sonora ("La parte de Amalfitano"); la pintura de un guatemalteco que anuncia un futuro ominoso (Nocturno de Chile); o el retrato más radical de los últimos años, que incluye una mano disecada del propio artista ("La parte de los críticos"), son ejemplos característicos. Algo similar ocurre con los Escritores Bárbaros (Estrella distante), cuya literatura tenía por estrategia someter "los libros a un proceso de degradación que Delorme llamaba humanización”. No se los exponía a la naturaleza desértica, sino a los humores de la naturaleza humana. Stendhal, Hugo y Balzac retornan no solo para ser leídos, sino también defecados, orinados, ensangrentados y semenizados. De ahí que la figura de Arcimboldo, y esta será la hipótesis que quiero desarrollar, no solo da cuenta de un mundo fragmentario o de una obra fragmentaria, como la de Bolaño. Reducir su obra a una cuestión de pura formalidad, a una metáfora estructural, no le hace justicia a su escritura, como tampoco, por el contrario, asumir de manera exclusiva sus reflexiones sobre el mal. De ahí mi intento por detenerme en "todo lo que conlleva una visión", pues el proceso compositivo y perspectivista de Arcimboldo debe ser leído al mismo 
tiempo que la ruina de la que da cuenta, pues es a partir de ambas estrategias que Bolaño configuró 2666, si bien no de manera exclusiva, pues, como ha señalado lúcidamente Anna Topczewska,"la instalación con el Testamento geométrico [en "La parte de Amalfitano"] constituye una mise en abyme que refleja el libro que el lector tiene en sus manos" (2013). Si esta hipótesis es correcta, podríamos pensar entonces que el recurso al arte plástico de Bolaño está inextricablemente inscrito en la textualidad de su obra. De ahí que las notas que siguen están en deuda con la propuesta de Topczewska, pues fue su lectura la que me llevó a mirar con distancia o a reparar más bien en la importancia de la distancia, para pensar el lugar de Arcimboldo en su obra.

No hace mucho, Sergio Marras publicó un pequeño libro bajo el título El héroe improbable (Cómo Arturo Belano siempre quiso ser Benno von Archimboldi) (2011). Para no darle vueltas al asunto, señalo de entrada que ambas partes del título son improbables, no tienen asidero. En primer lugar, toda la narrativa de Bolaño se estructura a partir de la imposibilidad de la epicidad, en otras palabras, en Bolaño no hay héroes, a veces ni siquiera personajes, sino espectros, pues, como magistralmente ironiza en "La parte de los críticos", habitamos un descampado radical que no da lugar a la épica. Pero la crítica, perdida en el desierto, no lo ha percibido, al confundir héroe con personaje. Y si Belano no es un héroe, Archimboldi tampoco es su alter ego ni un anti-héroe, y no lo es porque Belano es un tipo de escritor completamente opuesto al novelista alemán, cuya mediocre escritura está a punto de recibir el premio nobel. Cómo comparar a un Belano en África, con un Archimboldi jardineando en Venecia... es más, bien podríamos pensar al escritor alemán como una especie de Bartleby, que copia lo que recuerda de los cuadernos de Boris Ansky o de aquel libro que robó cuando niño y no se cansó de leer, Algunos animales y plantas del litoral europeo. Pero si me atrevo a señalar que Archimboldi es un escribidor, es porque la misma parte que habla de él nos da la clave para ello. En el castillo de Drácula, mientras Hans Reiter hacía de mesero, el general Entrescu señaló lo siguiente:

no era extraño, si uno contemplaba desapasionadamente los grandes hechos de la historia (incluso los hechos en blanco de la historia, aunque esto último, por supuesto, nadie lo entendió), que... un ser 
anodino o un mediocre de alma buena se convirtiera, con el paso de los siglos, en un faro de sabiduría, un faro magnético capaz de hechizar a millones de seres humanos, sin haber hecho nada que justificara tal adoración, vaya, sin siquiera haberlo pretendido o deseado $(2666,856-857)$.

No creo que haya mejor manera de describir a Benno von Archimboldi, un ser baladí que, sin desear la fama, sin desear siquiera las flores del campo intelectual, escribe, publica y viaja. Es más, recordemos que el mítico Archimboldi le arrendó una máquina de escribir, aquella con la que borronearía sus primeros libros, a un escritor o ex escritor al que la guerra le abrió los ojos, y le hizo comprender que "escribir era inútil" $(2666,984)$. Este mismo Bartleby de la literatura, que prefirió dejar completamente la escritura, le dice al joven Reiter que "toda obra que no sea una obra maestra es... una pieza de un vasto camuflaje" (984). Y su futura obra por supuesto que no es ni será una obra maestra... de manera que el autor de D'Arsonval, La máscara de cuero, La ciega, El bibliotecario, Bifurcaria bifurcata, y un largo etcétera no hace sino encubrir al autor de una verdadera obra maestra que secretamente acontece. Como los cuadros de Arcimboldo, la escritura de Archimboldi pareciera ocultar algo que no vemos a simple vista. Aquel que dejó de escribir, y que lo hizo porque se dio cuenta de "que jamás lograría acercarme o internarme en aquello que llamamos una obra maestra" (982), parece prevenir al joven Reiter, le habla de un escritor que, sin percibir la mirada testimonial de su esposa, se afana en la escritura, pero "en el interior del hombre que está sentado escribiendo no hay nada... Cuánto mejor haría ese pobre hombre dedicándose a la lectura”, precisamente un ejercicio que no realizó Reiter por muchos años y que apenas hará de ahí en adelante. Pero el aspirante lo escucha impertérrito y parece olvidar que la esposa de aquel escritor solo ha visto "el cascarón de la literatura. Una apariencia" (983). "¡Es necesario que haya muchos libros, muchos pinos encantadores, para que velen de miradas aviesas el libro que realmente importa", concluye el exescritor, en un tono que pareciera estar invitando a su oyente a cubrir la obra que realmente importa, y vaya que si será un autor prolífico Hans Reiter, puesto que "quienen verdad está escribiendo esa obra menor es un escritor secreto que sólo acepta los dictados de una obra maestra" (983).

Insisto, por tanto, que Archimboldi es un mal escritor, un pésimo escritor, cuya vasta producción oculta, como diría Derrida, una obra maestra por venir. Y si hay confusión en ello, se debe a que Bolaño, como Arcimboldo, encripta, vuelve ambigua, perspectivista, la apreciación que uno podría hacerse respecto 
de un escritor al que la fama le ha llegado tarde y azarosamente, aunque de manera tal que induce a creer que se está ante un escritor magistral. De ahí que valga la pena recordar, con el Barthes que escribiera un bello ensayo sobre el pintor italiano, que encriptar

[s]ignifica ocultar y no ocultar al mismo tiempo; el mensaje está oculto en cuanto el ojo es desviado del sentido general por la atracción del detalle; ve, primero, las frutas o animales amontonados; solo gracias a un esfuerzo de distanciamiento, cambiando el nivel de la percepción, capta otro mensaje, un aparato hipermétrope que, a modo de código de descifrado, permite percibir, de repente, el sentido global, el sentido "verdadero" (Arcimboldo 17. Cita levemente modificada).

He ahí la solución a nuestro problema: la confusión respecto de quién escribe una obra maestra. Creemos que es Archimboldi, puesto que hemos estado leyendo la novela sin tomar distancia, sin preguntarnos si en verdad los críticos (Pelletier, Espinoza, Morini y Norton)-“atorrantes" (985) engendrados por las universidades, al decir del exescritor-, que supuestamente hacen de la distancia una práctica, son los agentes capacitados para reconocer a ese "escritor secreto que sólo acepta los dictados de una obra maestra". Habría que recalcar que un escritor secreto es aquel que escribe, por poner un ejemplo, a lo Kafka, no Archimboldi, que si bien es un autor desconocido, es bastante prolífico, y su nombre es lo menos secreto que pueda encontrarse en la escena literaria ${ }^{1}$. No, el verdadero autor de una obra maestra parece estar en el por venir. Mientras, señala el exescritor "la mayor parte de los escritores se equivocan o juegan. Tal vez equivocarse y jugar sea lo mismo, las dos caras de la misma moneda. En realidad nunca dejamos de ser niños, niños monstruosos llenos de pupas y de varices y de tumores y de manchas en la piel" (984. Énfasis agregado). Repito esta última frase: "niños monstruosos llenos de pupas y de varices y de tumores y de manchas en la piel”. He aquí,

\footnotetext{
"Un bosque que crece a una velocidad vertiginosa, un bosque al que nadie le pone freno, ni siquiera las Academias, al contrario, las Academias se encargan de que crezca sin problemas, y los empresarios y las universidades (criaderos de atorrantes), y las oficinas estatales y los mecenas y las asociaciones culturales y las declamadoras de poesía, todos contribuyen a que el bosque crezca y oculte lo que tiene que ocultar, todos contribuyen a que el bosque reproduzca lo que tiene que reproducir, puesto que es inevitable que así lo haga, pero sin revelar nunca qué es aquello que reproduce, aquello que mansamente refleja” (985).
} 
una vez más, cuerpos y rostros feos, que dan asco, como los que vio Urrutia Lacroix, como los que pintó Arcimboldo.

De manera que Marras yerra cuando afirma que "B [el narrador, no Bolaño] crea a su personaje Archimboldi con características que le hubieran gustado que fueran las suyas" (166), y yerra una vez más cuando dice ver a "un nuevo Bibliotecario de Guiseppe Arcimboldo [Bolaño mismo]. Lo crea una constelación de personajes, historias y voces que prefiguran dos conocidas siluetas: la de Arturo Belano y la de Benno von Archimboldi" (172-173).

Si me detengo en el libro de Marras es porque tiene como hipótesis de lectura precisamente El bibliotecario, de Arcimboldo, obra que supuestamente permitiría comprender formalmente la narrativa de Bolaño. Como metáfora, puede funcionar, pero como señalé anteriormente, esto es solo una perspectiva. Marras, dice en su libro, recorrió museos y librerías buscando la obra del pintor italiano: "Los cuatro elementos, Las cuatro estaciones, El asado, muestras materiales que -a su juicio- gestan nuevos mundos capaces de suscitar, como en un big-bang, cientos de significados que no sabemos si se cruzarán alguna vez formando universos mayores que podremos percibir o se diluirán en la nada" (21). Error. "El arte de Arcimboldo - escribió Barthes-no es indeciso, apunta claramente hacia una dirección determinada: su lenguaje es muy asertivo" (Arcimboldo 19). Tampoco su repertorio es infinito, agrega el semiólogo francés, para quien en estas pinturas "todo tiene siempre un sentido, se lea como se lea, pero ese sentido no es nunca el mismo" (22). Incluso los temas de Arcimboldo, por lo menos aquellos a los que debe su fama, son reducidos: cabezas y retratos de familia. No, Arcimboldo (así como Bolaño) no despliega una obra que puede significar cualquier cosa, más bien pone en práctica una obra que da cuenta de la podredumbre en medio de la cual la obra misma se desarrolla, acontece.

Por otra parte, pensar que El bibliotecario es un cuadro que alegoriza la pasión por los libros y la escritura equivale a contemplar desde un angélico lugar la obra. Si Barthes está en lo correcto cuando afirma que el procedimiento de Arcimboldo es doble, puesto que primero, en el nivel de la analogía, "apela simplemente al sentido común y plantea la cosa más banal del mundo" (10), para luego hacer que la analogía enloquezca llevándola hacia su extremo, entonces la obra de Arcimboldo se desliza hacia un sentido completamente inesperado e inquietante: se desliza hacia su contrario. Cuando ello ocurre es porque la analogía se ha convertido en metáfora y, por lo tanto, ya no basta la mirada ingenua de la sensatez. "Las metáforas de Arcimboldo", aventura Barthes, "deshacen objetos familiares para producir otros, nuevos, extraños, 
mediante una clara imposición (una más) que nace del trabajo visionario (y no solo de la capacidad de captar similitudes)" (20). Lo anterior implica que "Todo puede acabar significando su contrario" (22).

¿Y si El bibliotecario no refiriera la pasión por la literatura, como parece afirmar Marras, sino el fetichismo por la acumulación, no un placer por el conocimiento, sino el simple y material afán de la adquisición? Si nos abstraemos o si nos distanciamos más bien de la idea libresca que ha dominado su comprensión, podríamos reparar en que la representación no da cuenta de alguien que comparta sus libros, sino de quien los atesora. Su brazo derecho, recogido, pareciera estar protegiendo un (su) tesoro y, cosa curiosa si pensamos en las otras pinturas de Arcimboldo, una cortina cubre su lado izquierdo y lo hace de manera tal que no es difícil imaginar que pronto desaparecerá tras ella.

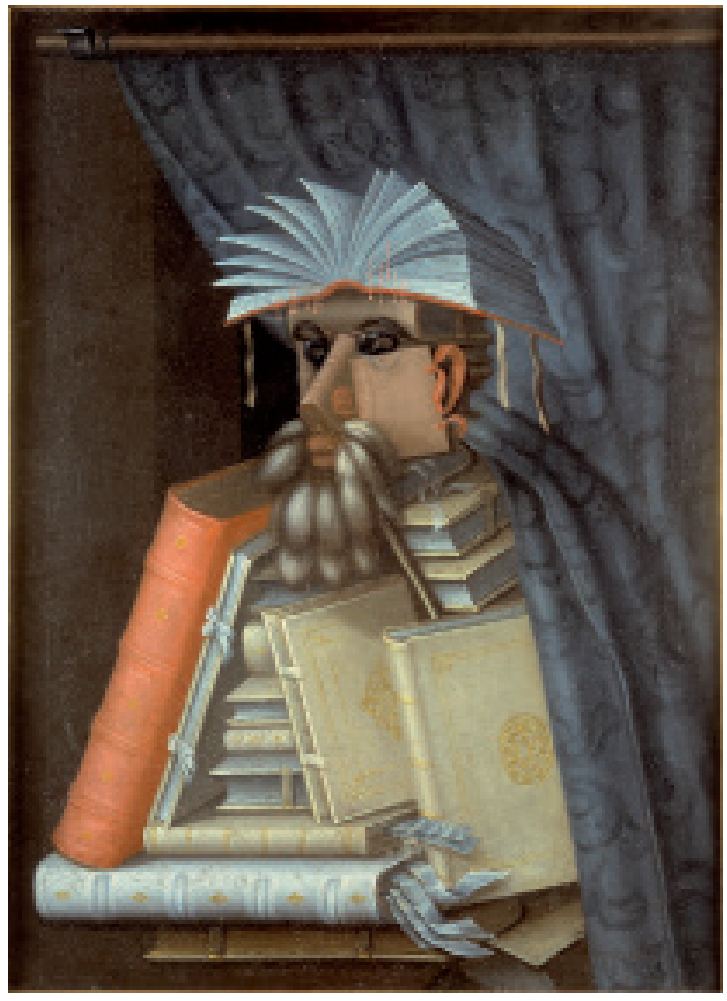

El bibliotecario, c. 1570 (Skokloster Slott, Estocolmo) 
En otros términos, pero similar, es la lectura que propuso hace unos años K. C. Elhard (2005) en un pequeño ensayo donde da cuenta de la posible influencia de La nave de los necios (Das Narrenschiff) en esta pintura de Arcimboldo. Dedicada a retratar los locos que circulaban por el mundo, el libro de Sebastián Brant contiene un capítulo titulado "De los libros inútiles", cuyo inicial verso es el siguiente: "El primer danzante soy en el baile de los necios, pues sin provecho muchos libros tengo, que ni leo ni entiendo" (94). Y continúa así:

Confío en mi biblioteca. De libros tengo gran tesoro, aunque en ellos entiendo muy pocas palabras, y los tengo en tal veneración, que hasta los defiendo de las moscas... Me contento con ver muchos libros ante mí..., pero leo poquísimo en ellos. ¿A qué iba a querer romperme la cabeza y agobiarme completamente bajo el peso del saber? Quien mucho estudia se vuelve fantasioso. Yo me tengo, no obstante, por un señor y pago a uno que aprende para mí (95).

Para Elhard "es bastante probable que El Bibliotecario evocara los pensamientos de este coleccionador de libros inútiles" ("Reopening the Book"121), es más, este loco es mostrado como un "diletante ignorante para el que los libros son objetos de deseo más que objetos de estudio" (120). Además, varias serían para Elhard las semejanzas entre la pintura de Arcimboldo y la ilustración que acompaña al libro de Brant. El plumero, presente en ambos, referiría la preservación de los libros, "enfatizando [con ello] la naturaleza física de la colección y el foco materialista del coleccionador" (121). Pero veamos mejor la ilustración del La nave de los necios: 


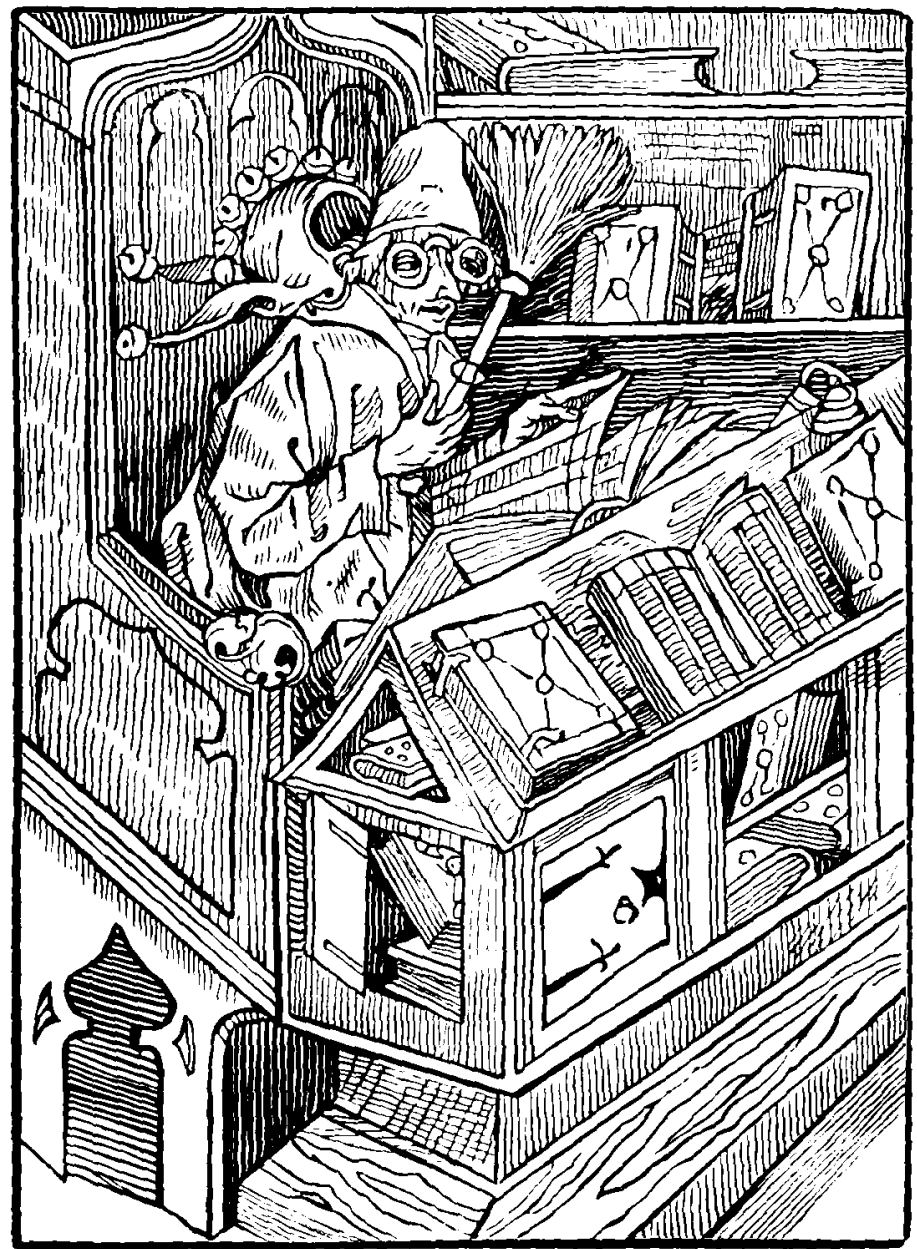

La semejanza es notable. Solo habría que añadir que la cabeza del bibliotecario arcimboldiano, con sus colgantes, estaría literalizando al loco de Brant y cuando uno lo ve así, no es difícil pensar que el pintor italiano no ha hecho sino ridiculizar a su figura, pues el pelo (único libro abierto), los ojos y el bigote no parecen estar dando cuenta de una persona muy seria. "Sin duda", afirmó Michel Foucault en su famosa Historia, "la locura tiene algo que ver con los extraños caminos del saber”, y agrega: 
El primer canto del poema de Brant está consagrado a los libros y a los sabios; y en el grabado que ilustra este pasaje [...] vemos al Maestro, como en un trono, en su cátedra atestada de libros; detrás del birrete de doctor, lleva el capuchón de los locos, adornado con cascabeles [...] si el saber es tan importante en el reino de la locura, no es porque ésta conserve aquellos secretos; es, al contrario, el castigo de una ciencia inútil y desordenada (Historia de la locura 43-44).

Lejos entonces se encuentra Arcimboldo de representar la pasión por los libros y la literatura, como afirmaría una mirada un tanto ingenua. Este bibliotecario no es un lector serio y protector del saber, sino un bufón acaparador que navega junto a otros necios desconsiderando la ciencia que porta la escritura.

Por otra parte, sabemos que Brant escribió un poema laudatorio para celebrar la coronación de Maximiliano en 1486 y más tarde un discurso en honor a su sucesor Carlos V, ambos pertenecientes a la casa de los Habsburgo, la misma para la que trabajará después Arcimboldo, bajo las órdenes de Maximiliano II, a quien llegó a retratar bajo el nombre de Vertumno.

De manera que, siguiendo nuevamente a Barthes, en el que tal vez sea un de los más brillantes escritos sobre Arcimboldo, del afán por el saber podemos pasar muy bien a la codicia, aún más si pensamos que por aquellos locos años, la emergencia de la imprenta generó un inusitado interés por el acaparamiento de los libros que salían de sus entrañas. Bien lo sabía Brant que decidió que este necio coleccionista fuera el que comandara la nave que hacia ningún lugar se dirigía, un loco que protegía del polvo su fortuna, pues en su locura posiblemente percibía que la naturaleza tampoco respeta las letras.

Sorpresivamente, El bibliotecario es también el título de un libro que escribió un tal J. M. G. Arcimboldi, personaje de Los sin sabores del verdadero policía, una novela que si bien llegó a tener tres borradores, Bolaño nunca publicó, y posiblemente no lo hizo pues todos o casi todos sus personajes fueron reescritos e inscritos en 2666, pero de una manera bastante distinta. Es como si Bolaño primero los hubiera dibujado y luego pulido o podado. Bueno, este tal Arcimboldi, de nacionalidad francesa, que comparte algunos títulos con Archimboldi, de nacionalidad alemana, publicó por Gallimard en 1966 una novela completamente arcimboldesca, pues su bibliotecario es, cómo no, un acaparador de originales. Su nombre lo indica claramente, pues a Jean, que es como se llama, le sigue el apellido Marchand, palabra francesa que en nuestra lengua refiere mercante, mercantil, comercial. Jean Marchand, escritor fracasado, comienza a trabajar como lector, posiblemente para Gallimard, y "de la noche a la mañana, se ve sepultado bajo cientos de 
novelas inéditas" (Los sinsabores 205). Marchand entonces se ve involucrado con escritores que, debido a su trabajo, recurren a él y hace que sientan que, de alguna manera, le están en deuda. Así es como "imperceptiblemente [los textos originales], van engrosando una colección de manuscritos inéditos que Marchand guarda celosamente en su casa" (206):

Entre esos manuscritos ajenos, su novela, El bibliotecario, inconclusa y perfectamente encuadernada, una belleza entre originales manoseados, borroneados, arrugados, sucios; un manuscrito hembra entre manuscritos machos. Marchand sueña que en una noche mágica e interminable los manuscritos rechazados hacen el amor de todas las maneras posibles con su manuscrito postergado: lo sodomizan, lo violan bucal y genitalmente, se corren en su pelo, en su cuello, en sus orejas, en sus axilas, etc., pero al llegar el amanecer su manuscrito no ha sido fecundado, es estéril (206).

Como vemos, un personaje que parece no haber abandonado la nave de los necios, un personaje que, comenzando una carrera "desinteresada" de lector, se transforma en un acaparador de originales. Pero un sueño lo atormenta, posiblemente como a todo aquel que tenga biblioteca, el sueño o una pesadilla más bien, de un gran incendio, como el que figuró Aldous Huxley en "Si mi biblioteca ardiera una noche" y luego le tocara vivir. Pero en la pesadilla de Jean, en el preciso momento en que las llamas comienzan su amenaza, aparece un "Mesías tonante que publicará todos los manuscritos sustraídos y que lo condenará al fuego eterno" (207). El fuego... ¿no es así como se titula una de las más famosas cabezas compuestas de Arcimboldo?

III

En 1920 nació Hans Reiter. No parecía un niño sino un alga. Canetti y creo que también Borges, dos hombres tan distintos, dijeron que así como el mar era el símbolo o el espejo de los ingleses, el bosque era la metáfora en donde vivían los alemanes. De esta regla quedó fuera Hans Reiter desde el momento de nacer. No le gustaba la tierra y menos aún los bosques. Tampoco le gustaba el mar o lo que el común de los mortales llama mar y que en realidad sólo es la superficie del mar, las olas erizadas por el viento que poco a poco se han ido convirtiendo en la metáfora de la derrota y la locura. Lo que le gustaba era el fondo del mar, esa otra tierra, llena de planicies 
que no eran planicies y valles que no eran valles y precipicios que no eran precipicios (797. Énfasis agregado).

Si se recuerda el cuarteto de obras que Arcimboldo reunió bajo el nombre de Los elementos, no es difícil percibir que los cuatro están presentes en el párrafo que narra el nacimiento del futuro Archimboldi: agua, tierra, viento y fuego, si bien este en potencia, pues lo que se nombra es el bosque, ese que contiene la leña que, encendida, figura el pelo de una de las figuras arcimboldianas.

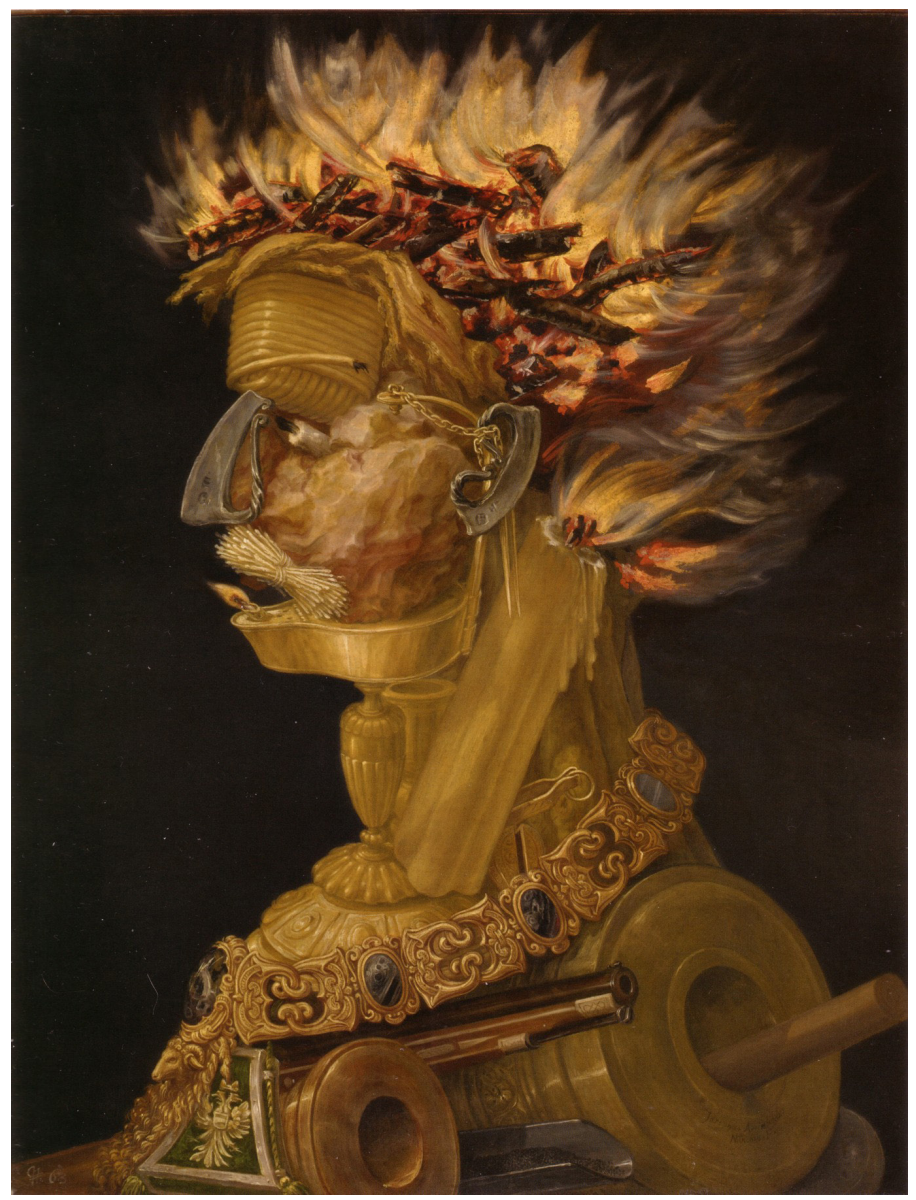

El fuego, 1570 (Kunsthistorisches Museum, Viena) 
Tengo la impresión, como señalé más arriba, si bien apresuradamente, de que Bolaño textualizó a Arcimboldo, y tal estrategia resulta aún más sintomática si reparamos en el hecho de que tanto Los elementos, como Las estaciones, son pinturas que tienen una clara impronta poética. Como mostró hace poco Thomas Dacosta Kaufmann (2010), además de pintor, Arcimboldo era poeta y tenía un amplio conocimiento del género, de manera que no solo la Metamorfosis de Ovidio, sino también y de manera fundamental, el nombre de Propercio, se hallan indefectiblemente unidos a su principal trabajo. Recordemos que en la obra del primero (Libro XIV), Vertumno, etrusco dios de las estaciones, esto es, dios del cambio y la mutación, intenta conquistar a Pomona, diosa romana de la fruta, vergeles y jardines, pero esta "que cierra por dentro los huertos, rehúye de los hombres y les prohíbe la entrada" (437), no permite que pretendiente alguno se le acerque, así que Vertumno, que nadie superaba en su amor a la diosa, "cambiándose en figuras distintas con frecuencia encontraba la forma de entrar, para disfrutar admirando la belleza de Pomona" (438). Cómo no llevaría esta atractiva imagen a que el mismísimo Giuseppe Arcimboldo escribiera su propio poema:

A che tanto stupore / e poi lieti ridere?

Certo che solo un mucchio mi credete

Di frutte e di verdura / Son Vertumno
¿Por qué tanto estupor / y luego encantada risa?

Ciertamente que sólo una canasta me creéis

De frutas y de verduras / Soy Vertumno

El primer verso de Arcimboldo, muestra lucidamente Kaufmann, se acerca de manera considerable al primer verso de una de las elegías de Propercio, que el pintor seguramente conoció en una traducción italiana, "A che ti meravigli di vedere", verso que continúa así: "Tante forme in un corpo? Se m'ascolti / Che sia Vertumno tu potrai sapere" (citado en Kaufmann 91). Una posible traducción sería la siguiente: “¿Tantas formas en un cuerpo? Si me oyes / que soy Vertumno sabrás". Esta elegía refiere gran parte de los elementos que constituyen las pinturas estacionales de Arcimboldo, tales como espigas, racimos, ciruelas otoñales, manzanas, e incluso leemos un verso magistral del poeta romano: "Mi naturaleza se adapta a cada una de las formas: / en la que tú desees, cámbiame y seré hermoso" (211). 


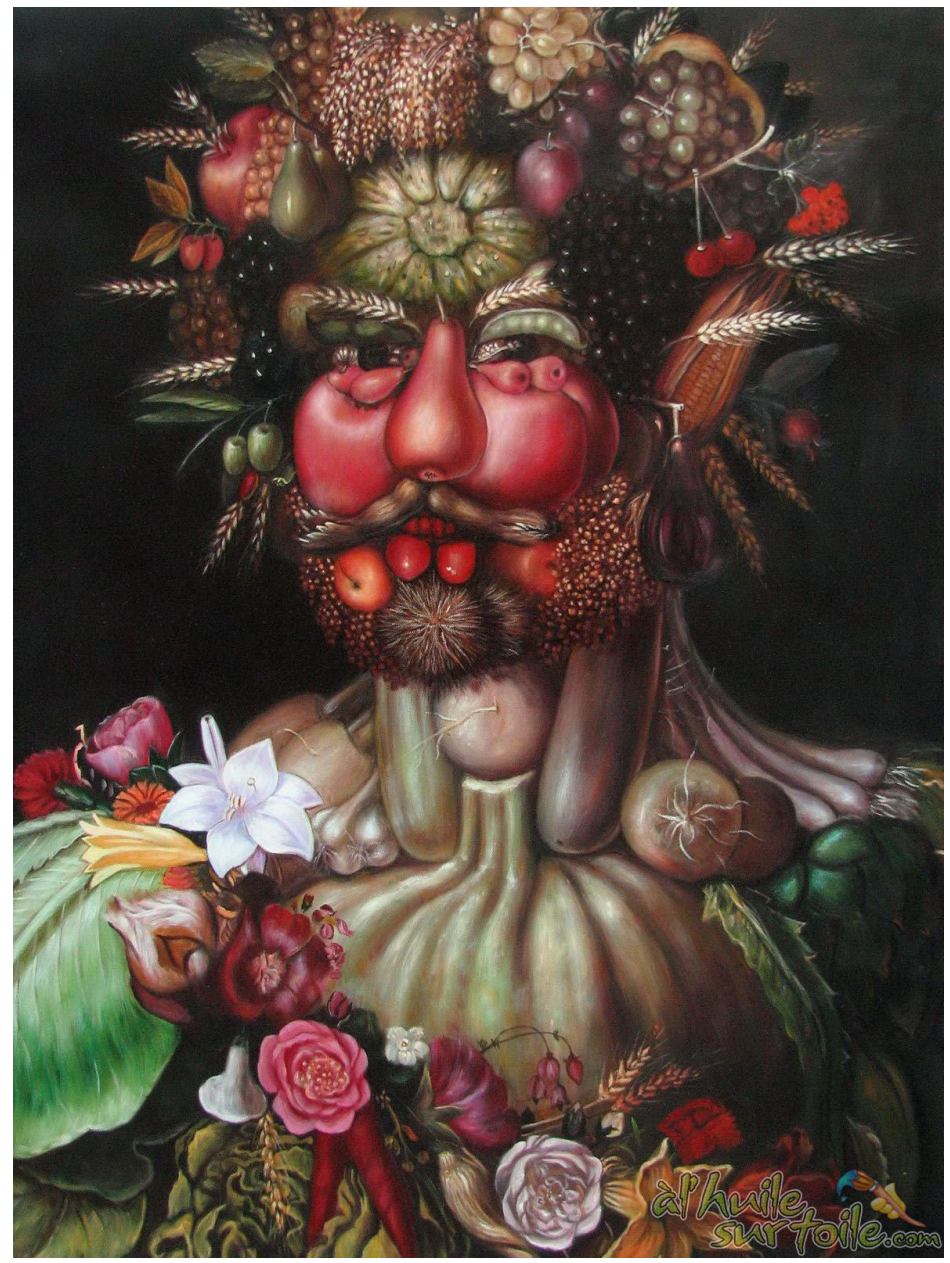

Vertumno, 1590-1591 (Skoklosters slott, Suecia)

Para Kaufmann, el retrato de Rodolfo II, que Arcimboldo también llamó Vertumno, "deriva gran parte de su imaginería visual de las características descritas originalmente en el poema de Propercio" (Arcimboldo: Visual Jokes 92), aunque posiblemente a partir de la versión italiana a la que se podría haber tenido acceso en aquel tiempo. Relevante es en este punto la relación con la política, pues Rodolfo se nos aparece así como aquel que domina no solo sobre sus súbditos, sino también sobre la naturaleza misma. Es más, 
con una lúcida distancia, podemos percibir que estaciones y elementos están explícitamente marcados por símbolos de los Habsburgo, lo que da cuenta de una "secuencia de correspondencia [que] es extendida desde el macrocosmos al microcosmos y de ahí al cuerpo político" (100). Y sobre todos y todo domina Rodolfo II, Vertumno en figura.

No obstante la potencia de este vínculo, lo que me interesa destacar es la forma en que Arcimboldo "adapta la imaginería visual de la poesía a la construcción poética del arte visual" (Arcimboldo: Visual Jokes 92), porque Bolaño, que también tituló Vertumno a unos de los libros de J. M. G. Arcimboldi, hace precisamente lo inverso, esto es, adapta la construcción plástica del arte a la imaginería visual de su escritura, devolviendo así a la poesía una imagen que le había sido confiscada, pero lo hace de tal manera que su proceder no responde a la hermosura de la que se jacta el Vertumno de Propercio, sino a lo grotesco y caduco de los retratos arcimboldianos.

Que a los seis el niño Reiter haya robado el libro Algunos animales y plantas del litoral europeo no es casual, pues fue a partir de él que comienza a indagar en el mundo, dado que "lo tenía dentro de la cabeza, como suele decirse" $(2666,799)$. Y "mientras buceaba", nos cuenta el narrador, "iba pasando páginas lentamente. Así descubrió a la Laminaria digitata, que es un alga de gran tamaño, compuesta por un tallo robusto y una hoja ancha, tal como decía el libro, en forma de abanico de donde salían numerosas secciones en tiras que parecían, en realidad, dedos" (799-800), similares, quisiera imaginar yo, a esos largos dedos con los que el bibliotecario cobija sus libros. Pero al niño Reiter no le bastaba con ver esos animales y esas plantas del litoral europeo, ya que muy pronto comenzó a dibujarlas (800). "Dibujó", por ejemplo, a "la Ascophyllum nodosum, que es un alga parda de patrón desordenado que presenta unas ampollas ovoides a lo largo de sus ramas. Existen, entre las Ascophyllum nodosum, algas diferenciadas macho y hembra que producen unas estructuras frutales similares a pasas" (800-801). En fin... Reiter leyó y releyó este libro por más de una década, incluso se lo llevó a la guerra. Y fue lo único que leyó hasta que Hugo Halder, luego de preguntarle si sabía leer, le dijo que podía tomar prestado un libro de la biblioteca. "El azar o el demonio quiso que el libro que Hans Reiter escogió para leer fuera el Parsifal, de Wolfram von Eschenbach" (821).

Hans leyó de principio a final el Parsifal, a veces en voz alta, mientras estaba en el campo o mientras recorría el camino que lo llevaba de su casa al trabajo, y no sólo lo entendió, sino que también le gustó. 
Y lo que más le gustó, lo que lo hizo llorar y retorcerse de risa, tirado sobre la hierba, fue que Parsifal en ocasiones cabalgaba (mi estilo es la profesión del escudo) llevando bajo su armadura su vestimenta de loco (823. Énfasis agregado).

¿Se habrá identificado el joven Reiter con Parsifal, un personaje entresacado de la ficción, un personaje que además de soldado, era jinete al igual que él, tal como nos lo indica su apellido alemán? Que pensara "que bajo su uniforme de soldado de la Werhmacht él llevaba puesta una vestimenta de loco o un pijama de loco" (837) pareciera indicarnos que sí. Deberíamos agregar que Eschenbach en su Parzival, cuyo personaje debajo de la armadura efectivamente vestía de bufón (Parzival 95), le comenta al lector: "No sé leer ni escribir. Muchos hacen nacer la poesía en la erudición. Esta historia navega sin el timón de los libros. Antes de que esta historia se tuviera por un libro así, preferiría estar desnudo y sin toalla en el baño" (73). Se dice que Eschenbach, cual aedo, tenía una memoria prodigiosa y se hacía leer, archivando un material que luego devolvería en verso para que otros lo escribieran. Como sea, se trata de un personaje que de alguna manera se emparenta con el bibliotecario de Brant y todavía más con los necios que navegan sin destino, pero creyendo que siguen alguno.

\section{IV}

Llegados a este punto, podemos recién detenernos en lo que creo es uno de los puntos centrales de la figura de Arcimboldo en la narrativa de Roberto Bolaño y para ello recurriré una vez más al ensayo de Barthes. Lo que me interesa de la lectura de Barthes es aquello que, siguiendo a Borges, podríamos llamar la obra invisible de Arcimboldo, una obra que, veremos pronto, es también la de Bolaño:

Las cabezas de Arcimboldo son monstruosas porque todas ellas, sea cual sea la gracia del tema alegórico (el Verano, la Primavera, la Flora, el Agua), remiten a una desazón esencial: el pulular. La mezcolanza de cosas (vegetales, animales, niños), hacinadas en desorden (antes de poder alcanzar la inteligibilidad de la figura final), evoca una vida de larva, una maraña de seres vegetativos, gusanos, fetos, vísceras, 
que están cerca del umbral de la vida, aún por nacer y, sin embargo, ya putrefactos $(30)^{2}$.

Lo que tenemos aquí, en estos cuadros de Arcimboldo, es una mezcla radical de lo animal y lo vegetal, lo animal y lo humano, todo lo cual no es sino un exceso grotesco que Barthes nombra como metamorfosis, y cuyo principio articulador es "que la Naturaleza no se detiene" (31). Para ejemplificar, consideremos la Primavera: "no deja de ser normal que se la represente como una mujer tocada con un sombrero de flores... pero Arcimboldo no se para, sigue", dice el escritor francés; "las flores bajan del sombrero al cuerpo, invaden la piel, hacen la piel: una lepra de flores invade el rostro, el cuello, el pecho" (31). Para señalarlo de manera clara, "estas cabezas compuestas son cabezas que se descomponen" (25), que se pudren, que caminan hacia la muerte, de manera que aquello que Arcimboldo pinta no es, o no es tan solo, una imagen alegóricamente compuesta, sino un proceso de descomposición, o para decirlo con palabras de Adorno, Arcimboldo figura la metamorfosis del "momento en que la naturaleza y la historia se hacen mutuamente conmensurables" (Dialéctica negativa 330) en la caducidad. Arcimboldo pinta la transitoriedad de la existencia. Vertumno, en hombre figurado, descendió a la tierra (literalmente) y en ella morirá, pues está "compuesto" de los productos que de ella nacen y que a ella, descompuestos o arruinados, vuelven... que Rodolfo II haya sido su encarnación afirma este principio.

Si tal lectura es posible, entonces la alegoría arcimboldiana estaría más cerca de lo que hemos pensado de la alegoría trabajada por Walter Benjamin en su libro dedicado al drama barroco alemán, donde se explicita que la historia se plasma en una calavera, y ésta es el emblema de la alegoría, que "encuentra su más cumplida expresión en la ruina" ("El origen del “Trauerspiel”" 205). La crítica argentina María Stegmayer fue quien afirmó que "[l]a parte de los crímenes" está modulada bajo esta idea, pues la historia natural estaría magistralmente inscrita en los cuerpos y huesos que el desierto

\footnotetext{
Un poco antes, Barthes había señalado: "Estamos aquí como ante una composición musical: hay un tema de base (el Verano, el Otoño, Calvino), pero cada variación produce un efecto distinto. Aquí, el Hombre estacional acaba de morir, el invierno tiene aún el color rojizo de un otoño que no ha[ce] mucho se alejó; está ya exangüe; ahí... el Hombre-Invierno ya es solo un cadáver en avanzado estado de descomposición... el Calvino de Bérgamo... se va deteriorando, desmoronándose, haciéndose gris... Es como si, a cada instante, la cabeza oscilara entre la vida maravillosa y la muerte horrible" (24-25).
} 
va haciendo suyos ("Agujeros negros" 127). De manera que fue su ensayo, junto al de Barthes, lo que me llevó a pensar que no solo una parte, sino el libro entero, todo 2666, estaría atravesado por la idea de ruina y caducidad, pues Benno von Archimboldi ha sido literalmente textualizado a partir de figuras en tránsito hacia la descomposición, y es como tal que articula las cinco partes de la novela, lo que permite señalar, junto a Stegmayer, que "lo que otros han concebido como imágenes apocalípticas es para nosotros el paisaje alegórico de un presente en ruinas" (125). A propósito de Arcimboldo, Barthes señaló que "semejante ejercicio de imaginación no pertenece sólo al ámbito del arte, sino también al del saber: plasmar metamorfosis... es un acto de conocimiento" (31-32). Si esto es así, entonces Bolaño ha plasmado en su obra una particular visión de nuestro tiempo, un tiempo anclado en lo acontecido a lo largo del siglo XX, signado por la "historia natural de la destrucción".

No está demás recordar que fue W. G. Sebald quien llevó la idea de historia natural del barroco hacia la literatura del siglo XX y lo hizo a partir de un conjunto de obras que se hicieron cargo de los bombardeos aéreos que convirtieron en ruinas, que redujeron a escombros durante la segunda gran guerra, algunas ciudades alemanas, devolviendo "a partes enteras de la población al nivel de desarrollo del coleccionista" (75) - no sin antes señalar que este acontecimiento fue escasamente tratado-:

La amplia distancia que media entre el sujeto y el objeto del proceso narrativo implica algo así como la perspectiva de la historia natural, en la que la destrucción y las formas tentativas determinadas por ella actúan como experimentos biológicos donde lo que importa a la especie es "romper su forma y abjurar del nombre de hombre" ("Entre historia e historia natural" 75).

Abjurar del nombre de hombre es abjurar de los ropajes con que la idea de civilización ha tratado de sustraer al hombre de su condición natural. Es la caída de la máscara o, mejor dicho, de la adornada cáscara con la que pretendemos extender ese "minuto altanero y falaz", al decir de Nietzsche, y pensar que somos algo, o que poseemos algo que, a diferencia de los animales, ha logrado domeñar la (nuestra) naturaleza. Lo que la guerra permitió, parece decirnos Sebald, fue percibirnos sin "el enmascaramiento, el convencionalismo encubridor, la escenificación ante los demás y ante uno mismo" (Nietzsche, Sobre verdad y mentira 23). Un signo como este permite comprender que "la catástrofe colectiva marca el punto en que la historia amenaza volver a ser 
historia natural" (Sebald, "Entre historia e historia natural" 77), esto es, ruina y decadencia. Se comprende entonces la radicalidad de esta idea, radicalidad que, por cierto, nada tiene que ver con el hecho de que la naturaleza tenga una historia o, al revés, que la historia tenga naturaleza. Esta antítesis fue la que se encargó de desechar hace ya unas décadas Adorno, remarcando, por el contrario, que la historia natural tiene lugar allí donde la naturaleza se presenta como historia, esto es, cuando se presenta en su transitoriedad o cuando la historia se expresa en una calavera.

Sebald muestra que quienes se han atrevido a una narración tal han recurrido a una distancia a través de la cual lograr una precisión en la descripción, como lo hiciera el doctor Michihiko Hachiya en su libro dedicado a la destrucción de Hiroshima, pues la suya era, citando a Elias Canetti, la forma literaria indispensable para nuestros tiempos, la escritura de alguien que sabe y que tiene los ojos muy abiertos (La conciencia de las palabras 148). De ahí que, para Sebald, "el intento de describir literariamente catástrofes colectivas... rompe necesariamente la forma de la ficción novelesca, que se debe a la visión burguesa del mundo" (81). El que algunos escritores pertenecientes a generaciones posteriores a la época de las guerras escriban como Hachiya, y sin envidiarle lucidez ni atrocidad a su experiencia, ya nos indica que, de cierta manera, la catástrofe, y sobre todo sus implicancias para la vida, constituye nuestra cotidianidad.

Luego de Adorno, quizá quien mejor ha reflexionado sobre la historia natural y su importancia para ciertas escrituras, sea Eric Santner. En On Creaturely Life, señala lo siguiente:

La historia natural, tal como Benjamin la entiende, refiere un rasgo fundamental de la vida humana, a saber, el hecho de que las formas simbólicas en y por las cuales esta vida es estructurada puedan ser vaciadas, perder su vitalidad, romperse en una serie de significantes enigmáticos, "jeroglíficos” que de algún modo siguen dirigiéndonos -bajo nuestra piel psíquica-, aunque nosotros ya no poseamos la llave de su significado. Para Benjamin, la historia natural, en última instancia, nombra la incesante repetición de ciclos de aparición y decaimiento de la búsqueda [orders] humana de significado, ciclos que están, para él -y aquí es donde la base schmittiana puede tener sentido-siempre conectados a la violencia (17).

Santner toma a su cargo tres autores del siglo XX, cuyas obras podemos encontrar atravesadas por esta concepción de la vida: Rilke, Benjamin y el 
mismo Sebald. No solo un modo alegórico de representación daría cuenta de su trabajo, sino también su comprensión radical de la transitoriedad de la vida. "El punto más hondo en que convergen historia y naturaleza se sitúa precisamente en ese elemento, lo transitorio", había señalado Adorno ("La idea de historia natural" 122). Tengo la impresión de que pocos como Bolaño han logrado inscribir en la literatura la fugacidad de la vida considerada desde su caducidad, puesto que lo que encontramos en sus obras, particularmente en aquella que no logró terminar completamente, es que asistimos a un momento en que no es necesaria la experiencia de la guerra, no es necesario vivir la destrucción, para asistir al retorno de lo natural reprimido, puesto que parece que son los horribles acontecimientos los que nos han domesticado y no nosotros a ellos. "Los griegos inventaron, por decirlo de alguna manera, el mal, vieron el mal que todos llevamos dentro, pero los testimonios o las pruebas de ese mal ya no nos conmueven, nos parecen fútiles" (338), leemos en 2666. No nos conmueven las muertes de la comuna de parís, no nos conmueven las miles de muertes provocadas por el tráfico esclavista, señala Albert Kessler en "La parte de Fate", como tampoco lo hacen los cientos de asesinatos o feminicidios que acontecen desde hace unos años en el norte de México. Pero sí nos impactan las noticias de un profanador de iglesias, la muerte de un personaje televisivo o la pérdida en el futbol de un penal. "Las palabras solían ejercitarse más en el arte de esconder que en el arte de develar" (339), sentenció el profesor Kessler. Ya no se necesita de una guerra para sentir el horror, este, como acabamos de comprobar el año recién pasado gracias a México, es parte de nuestra cotidianidad.

Si Bolaño escribe como Hachiya, su escritura entones se hace indispensable. Y de la misma manera en que en el médico japonés "la observación se centra, sin excepción, en los seres humanos" (148), lo mismo podríamos decir del escritor latinoamericano. Pero uno escribe en 1945, después de caída una bomba nuclear, y el otro a inicios del siglo XXI, desde su casa costera, y en ambos, sin embargo, nos encontramos con la narración de un drástico golpe a las formas viables de vida (Santner), un golpe similar al que la naturaleza asesta cuando se enseñorea con las ruinas, pues estás se someten a la misma fuerza que esculpió ríos y montañas, según la bella expresión de Georg Simmel. Ahora imaginemos cómo una fuerza así nos asalta, pero no pensemos que se trata, necesariamente, de una fuerza externa a nosotros mismos. La escritura de Bolaño narra ese golpe, narra la forma en la que la violencia ha desestructurado formas de vida, vaciando incluso a esta de sentido y responsabilidad hacia ella. Y narra por supuesto la continuidad de la vida 
luego de ese gran golpe, de esa violencia a la que nos hemos acomodado, a la que nos acostumbramos o que nos acostumbra a ella misma. Narra, en fin, un fin, el de la muerte haciéndonos dormir.

"Cuando ya no podía más, Ansky volvía a Arcimboldo. Le gustaba recordar las pinturas de Arcimboldo, de cuya vida ignoraba o fingía que lo ignoraba casi todo" (917). Ya señalé que Bolaño no tiene nada que ver con Archimboldi más que jugarnos con él una broma. Y si Bolaño ha de tener cercanía con alguno de los personajes de 2666, este podría ser Boris Ansky, porque como él, posiblemente también Bolaño fingía que lo ignoraba casi todo. Es más, si el escritor judío ruso decidió escribir un diario en las cercanías de sus enemigos, es dable pensar que no la transparencia, sino la criptografía fue lo que desarrolló. De manera que cuando Ansky escribe: "Cuando estoy triste o abatido... cierro los ojos y revivo los cuadros de Arcimboldo y la tristeza y el abatimiento se deshacen" (918), bien podría estar refiriendo lo contrario. El arte del reverso era una de las especialidades del pintor italiano. Por un lado una exquisita comida, por otro "la sonrisa atroz de un viejo mercenario que te mira, y su mirada es aún más atroz que su sonrisa, como si supiera cosas de ti" (917).

Si Bolaño, como he tratado de mostrar, tenía una lúcida comprensión de lo que se encuentra en la pintura de Arcimboldo -esto es, el agotamiento de la vida humana, el rápido tránsito de la vida hacia la muerte, con la violencia haciendo de escudero-, se podría decir que toda su obra es la memoria de un evento atroz que lastimosamente doma nuestro futuro.

\section{BIBLIOGRAFÍA}

Adorno, Theodor W. "La idea de historia natural". Actualidad de la filosofía. Trad. José Luis Arantegui. Barcelona: Paidós, 1991. 103-134.

Dialéctica negativa. Trad. Alfredo Brotons Muñoz. Madrid: Akal, 2005 [1970].

Barthes, Roland. Arcimboldo. Trad. Didier Holtz. Madrid: Casimiro, 2014 [1978].

Benjamin, Walter. "El origen del 'Trauerspiel' alemán”. Obras. Libro I/Vol. 1. Trad. Alfredo Brotons Muñoz. Madrid: Abada, 2006 [1928]. 217-459.

Bolaño, Roberto. 2666. Barcelona: Anagrama, 2007 [2004].

Nocturno de Chile. Barcelona: Anagrama, 2007 [2000].

Los sinsabores del verdadero policía. Barcelona: Anagrama, 2011.

Canetti, Elias. La conciencia de las palabras. Trad. Juan José del Solar. México: FCE, 1981. Brant, Sebastían. La nave de los necios. Sebastián Regales, ed. Madrid: Akal, 2011. 
Eschenbach, Wolfram von. Parzival. Trad. Antonio Regales. Madrid: Siruela, 1999.

Elhard, K. C. "Reopening the Book on Arcimboldo's 'Librarian'”. Libraries \& Culture 40.2 (2005): 115-127.

Foucault, Michel. Historia de la locura en la época clásica, tomo I. Trad. Juan José Utrilla. México: Fondo de Cultura Económica, 2006 [1964].

Kaufmann, Thomas Dacosta. Arcimboldo: Visual Jokes, Natural History, and Still-Life Painting. Chicago: University of Chicago Press, 2010.

Marras, Sergio. El héroe improbable (cómo Arturo Belano quiso ser siempre Benno von Archimboldi). Santiago: Ril, 2011.

Nietzsche, Friedrich. Sobre verdad y mentira en sentido extramoral. Trad. Manuel Garrido. Madrid: Tecnos, 2012.

Ovidio. Metamorfosis. Madrid: Espasa Calpe, 2007.

Santner, Eric L. On Creaturely Life. Rilke, Benjamin, Sebald. Chicago: University of Chicago Press, 2006.

Sebald. W.G. "Entre historia e historia natural". Campo Santo. Trad. Miguel Sáenz. Barcelona: Anagrama, 2007. 64-91.

Stegmayer, María. "Agujeros negros: violencia, fantasía y alegoría en "La parte de los crímenes”, de Roberto Bolaño. Raúl Rodríguez Freire, ed. Fuera de quicio. Bolaño en el tiempo de sus espectros. Santiago: Ripio, 2012. 117-132.

Topczewska, Anna. "Testamento geométrico. El "ready-made infeliz" como clave interpretativa de 2666". Manuscrito, 2013. 